Editorial

\title{
Small-Scale Energy Conversion of Agro-Forestry Residues for Local Benefits and European Competitiveness
}

\author{
Andrea Colantoni ${ }^{1, *(1)}$, Danilo Monarca ${ }^{1}$, Massimo Cecchini ${ }^{1}$, Enrico Maria Mosconi ${ }^{2}$ and \\ Stefano Poponi ${ }^{3}$ \\ 1 Department of Agricultural and Forestry Sciences (DAFNE), University of Tuscia, Via S. Camillo De Lellis, \\ 11100 Viterbo, Italy; monarca@unitus.it (D.M.); cecchini@unitus.it (M.C.) \\ 2 Department of Economicsn Engineering, Society and Business Organization, Tuscia University, \\ Via del Paradiso 47, I-01100 Viterbo, Italy; enrico.mosconi@unitus.it \\ 3 Faculty of Economics, Università degli Studi Niccolò Cusano, via Don Carlo Gnocchi 3, 00166 Roma, Italy; \\ stefano.poponi@unicusano.it \\ * Correspondence: colantoni@unitus.it; Tel.: +39-0761357356
}

Received: 14 December 2018; Accepted: 18 December 2018; Published: 20 December 2018

check for updates

\section{Introduction}

This special issue was founded after the creation of a department of excellence at the University of Tuscia (Viterbo, Italy). In particular, in the context of the Work Package 3 (WP3) objective, there is a need for innovation in the agricultural and forestry sectors for energy sustainability. Renewable energy sources and the rational use of energy represent an important agricultural and forestry resource in a local context against climate change [1-10]. The current way to produce, convert, and consume energy throughout the world is not sustainable. However, our economic growth and social development can be implemented only by means of an appropriate availability of energy services. Large plants present several problems: (1). high biomass supply; (2). authorization problems for the large plants; (3). Biomass conversion technologies more adapted to change biomass residual in energies. The small plants are a technology for future energy supply systems. The unique and advantageous point in the combination of residual biomass and small plants results from the fact that biomass is a renewable source of energy which can be used most efficiently using gasification technology $[4,9,11,12]$. Thermo-chemical processes can be seen as an energy-efficient technology for the transformation of biomass, especially lignocellulosic feedstock, into a syngas, which can be used for various use routes (heat, heat and power, gaseous as well as liquid biofuels, chemicals, etc.). The use of biomass for energetic purposes within Europe varies widely from country to country and from region to region, depending on the climate, the traditions in the use of the land, the available biomass and on the political and financial support for energy from biomass [13-18]. In some European countries where the energetic use of biomass is considerably supported by national programs (e.g., Austria, Denmark, Finland, and Sweden), biomass as a source of energy is already used to a remarkable degree. In Finland, biomass contributes with $17 \%$ to the fossil primary energy consumption. In Sweden, Portugal, and Austria the share of biomass use is between $12 \%$ and $14 \%$. The main biomass resources that are already widely used in Europe are: fuel wood in households for heating and for cooking; wood chips from thinnings and tree harvesting in district heating plants [19,20]; wood processing residues in the wood processing industry and in district heating plants; residual wood and bark from wood processing including recovered wood products (i.e., demolition wood) in the wood processing industry and power generation sector and pulping liquors in the pulp and paper industry (particularly in the Scandinavian countries). Biomass already contributes to the European energy supply to a certain 
extent, though, according to the assessments made above about the potential of biomass as a source of energy, this share could be considerably higher than it is today $[4,9,11]$. From the shares of the currently used fossil energy carriers and the calculated biomass potential, the maximum reachable share of biomass to cover the energy demand can be calculated. The following enumeration shows the results of such calculations: (i) Biomass resources below $10 \%$ of the fossil energy supply in the Netherlands, Belgium and Luxembourg, United Kingdom, Germany, and Italy; (ii) biomass resources between 10 and $30 \%$ of the fossil primary energy consumption in Denmark, Spain, France, Greece, Portugal and Austria; (iii) biomass resources above $30 \%$ of the fossil primary energy consumption in Ireland, Sweden, and Finland. Additionally, the share of the already-used biomass is analyzed against the background of the overall available biomass resources. This shows that, in nearly all of the EU-countries, only slightly more than $25 \%$ of the available biomass resources are currently used. In most countries, the share is even significantly lower. It is only higher in countries where the energetic use of biomass is promoted by governmental measures. The increasing demand for energy and related environmental concerns are the main drivers for the strong interest in biomass residues in the agro-forestry sector and in appropriate small- scale energy conversion. Biomass residues (e.g., prunings, thinnings and forest residues) constitute a highly promising (and currently largely under-used) feed stock with a significant potential to be converted into useful end products. This Special Issue proposal has the overall aim of developing a network around technologies for small-scale energy conversion of forestry residues for local benefit and European competitiveness. The following targets will be addressed: (i) to improve knowledge of different energy conversion processes for forest residues; (ii) to develop an expert group on forest biomass supply chains; (iii) to identify best practice for sampling of available forest biomass residues; and (iv) to create agro-forestry-scale energy districts. The purpose of this Special Issue is to publish high-quality research papers, as well as review articles, addressing recent advances on systems, processes, and materials for work safety, health, and environment. Original, high-quality contributions that have not yet been published, or that are not currently under review by other journals or peer-reviewed conferences, are sought.

\section{Papers in this Special Issue}

The special issue "Small-Scale Energy Conversion of Agro-Forestry Residues for Local Benefits and European Competitiveness" brings together some of the latest research results in the field of biomass valorization and process to energy production. It presents 20 papers, which deal with a wide range of research activities. We can divide the special issue in parts, as follows.

\subsection{Concept Paper}

The first contribution in this section explores the Agro-Forest Management and Soil Degradation in Mediterranean Environments: Towards a Strategy for Sustainable Land Use in Vineyard and Olive Cropland" by Maurizio Marchi, Carlotta Ferrara, Rita Biasi, Rosanna Salvia and Luca Salvati, in this article the landscape fragmentation typical of the Mediterranean region is the result of long-term settlement history and continuous socioeconomic interactions among countries. In complex agro-ecosystems of the Mediterranean basin, formulation of practical guidelines aimed at counteracting soil and land degradation, water depletion, rural area depopulation, and the loss of agricultural knowledge is imperative. Based on a multidisciplinary, integrated approach, the present contribution discusses the role of traditional agricultural systems in ecosystem services provision, considering together economic sustainability and the medium-term ecological benefits. A permanent monitoring of rural areas specialized in traditional crop production such as olive and vine may support optimal selection of cultivars finely adapted to a warm climate. A competitive agricultural system may consider human wellbeing, social equity, and conservation of natural resources, to ensure a high level of services for current and future generations. Recovery and conservation of agricultural resources provide positive externalities and social benefits at both local and regional levels. Understanding the multiple 
use and functions of tree crop landscapes will contribute to improve food security, land quality, and the provision of related ecosystem services.

\subsection{Case Report Article}

The second paper concerns the "Sustainable Land Use, Wildfires, and Evolving Local Contexts in a Mediterranean Country, 2000-2015" by Maurizio Marchi, Francesco Chianucci, Carlotta Ferrara, Giorgio Pontuale, Elisa Pontuale, Anastasios Mavrakis, Nathan Morrow, Fabrizio Rossi and Luca Salvati. Socioeconomic conditions and land management choices combine to affect changes in long-term wildfire regimes in Mediterranean-type ecosystems. Identification of specific drivers and dynamics at the local level is needed to inform land resource planning and to enhance wildfire management efficiency [14,16-18,21-28]. Therefore, investigating feedback relationships between wildfire and socioeconomic conditions at local and regional scales can reveal consistency in spatial and temporal patterns influencing wildfire frequency, intensity, and severity. This study assessed long-term wildfire characteristics in Greece - one of the most fire-prone countries in Europe-over two consecutive time periods characterized by economic expansion (2000-2007) and recession (2008-2015). An integrated, multivariate statistical approach was implemented to assess the latent relationship between socioeconomic forces and localized wildfire regime indicators. Changes in the number of fires at the wildland-urban interface and duration of wildfires were consistent with expectations [21]. Observed changes in the size of fires showed mixed results. Empirical findings of this study indicate analysis of wildfire regimes that takes into account both the socioeconomic and environmental factors in the overall territorial context of Mediterranean-type ecosystems, at both regional and local scale, may prove informative for the design of wildfire prevention measures in Greece.

\subsection{Review Article}

The third contribution is Monitoring and Optimization of the Process of Drying Fruits and Vegetables Using Computer Vision: A Review by Flavio Raponi, Roberto Moscetti, Danilo Monarca, Andrea Colantoni and Riccardo Massantini. An overview is given regarding the most recent use of non-destructive techniques during drying used to monitor quality changes in fruits and vegetables. Quality changes were commonly investigated in order to improve the sensory properties (e.g., appearance, texture, flavor, and aroma), nutritive values, chemical constituents, and mechanical properties of drying products. The application of single-point spectroscopy coupled with drying was discussed by virtue of its potentiality to improve the overall efficiency of the process. With a similar purpose, the implementation of a machine vision (MV) system used to inspect foods during drying was investigated; MV, indeed, can easily monitor physical changes (e.g., color, size, texture, and shape) in fruits and vegetables during the drying process. Hyperspectral imaging spectroscopy is a sophisticated technology since it is able to combine the advantages of spectroscopy and machine vision [22-24]. As a consequence, its application to drying of fruits and vegetables was reviewed. Finally, attention was focused on the implementation of sensors in an on-line process based on the technologies mentioned above. This is a necessary step in order to turn the conventional dryer into a smart dryer, which is a more sustainable way to produce high-quality dried fruits and vegetables [25].

\subsection{Article on the Sustainability Issues}

Rooting the Future; On-Farm Trees' Contribution to Household Energy Security and Asset Creation as a Resilient Development Pathway-Evidence from a 20-Year Panel in Rural Ethiopiaby Nathan Morrow, Luca Salvati, Andrea Colantoni and Nancy Mock. This paper study the most rural people globally cook with firewood or other sources of biomass. When biomass that has more productive uses is instead burnt, it is a sign of household-level energy insecurity. Burning crop residue and dung for fuel reduces the availability of fertilizer and fodder, as well as directly contributes to poor health outcomes. Ethiopia is largely deforested, and now many of Ethiopia's trees are on farms rather than in forests. The objective of this research is to investigate the relationship of on-farm 
trees to household-level energy security, rural livelihoods, and wellbeing. Using an econometric model with 20-year panel data from rural Ethiopia, we find on-farm trees contribute to building the household's most valuable asset: their home. By contributing to household-level energy security, we find on-farm trees increase crop residue availability for maintaining the rural household's second most valuable asset: their livestock. Large development efforts, including integrated water management projects and investment programs from the World Bank, are increasingly recognizing contributions of trees on farms, and environmental quality in general, as important contributing factors to meeting sustainable development outcomes. Asset creation related to on-farm trees and improved home biomass management provides a compelling pathway for building resilience, maintaining wellbeing, and reinforcing the foundation of rural livelihoods. The eighth article is Clustering or Scattering? The Spatial Distribution of Cropland in a Metropolitan Region, 1960-2010 by Andrea Colantoni, Ilaria Zambon, Maria Gras, Enrico Maria Mosconi, Alessandra Stefanoni and Luca Salvati. This article presents empirical results of a multivariate analysis run with the aim to identify (apparent and latent) socioeconomic transformations that shape the distribution pattern of cropland in a metropolitan region of southern Europe (Athens, Greece) over a sufficiently long time interval spanning from 1960 to 2010. The study area is representative of mono-centric cities expanding in an unregulated fashion and experiencing sequential cycles of economic growth and recession. Percent share of cropland in total municipal area increased moderately over time. A non-linear relationship with the distance from downtown Athens was also observed, indicating that the highest rates of cropland were observed at a distance ranging between 20 and $30 \mathrm{~km}$ from the inner city. A multivariate regression was run by decade at each municipality of the study area using 11 predictors with the aim to identify the factors most associated with cropland decline along urban fringes. Distance from downtown Athens, soil and climate quality, population growth rate, and competing land use were the most relevant factors correlated with cropland expansion (or decline) in the study area. Competing land use was particularly important for cropland decline in a first urbanization phase (1960-1980), while population growth rate-and hence an increased human pressure-was positively associated with agricultural areas in a subsequent phase (1990-2010). In these regards, per capita urban land had a non-linear spatial behavior, being correlated negatively with cropland in 1960 and 1970 and positively in 2010, possibly indicating a moderate change from a mono-centric model towards a more dispersed metropolitan configuration impacting distribution of agricultural areas. Empirical findings of this study suggest that effective strategies supporting peri-urban agriculture require a comprehensive knowledge of the local socioeconomic context and relevant biophysical conditions-specifically focusing on the dominant soil and climate attributes. The ninth article is Sustainable Land Management, Adaptive Silviculture, and New Forest Challenges: Evidence from a Latitudinal Gradient in Italy by Gianfranco Fabbio, Paolo Cantiani, Fabrizio Ferretti, Umberto di Salvatore, Giada Bertini, Claudia Becagli, Ugo Chiavetta, Maurizio Marchi and Luca Salvati. Aimed at reducing structural homogeneity and symmetrical competition in even-aged forest stands and enhancing stand structure diversity, the present study contributes to the design and implementation of adaptive silvicultural practices with two objectives: (1) preserving high wood production rates under changing environmental conditions and (2) ensuring key ecological services including carbon sequestration and forest health and vitality over extended stand life-spans. Based on a quantitative analysis of selected stand structure indicators, the experimental design was aimed at comparing customary practices of thinning from below over the full standing crop and innovative practices of crown thinning or selective thinning releasing a pre-fixed number of best phenotypes and removing direct crown competitors. Experimental trials were established at four beech forests along a latitudinal gradient in Italy: Cansiglio, Veneto; Vallombrosa, Tuscany; Chiarano, Abruzzo; and Marchesale, Calabria. Empirical results indicate a higher harvesting rate is associated with innovative practices compared with traditional thinning. A multivariate discriminant analysis outlined significant differences in post-treatment stand structure, highlighting the differential role of structural and functional variables across the study sites. These findings clarify the impact of former forest structure in shaping post-treatment stand attributes. Monitoring standing 
crop variables before and after thinning provides a basic understanding to verify intensity and direction of the applied manipulation, the progress towards the economic and ecological goals, as well as possible failures or need for adjustments within a comprehensive strategy of adaptive forest management. Another article is Operator Dermal Exposure to Pesticides in Tomato and Strawberry Greenhouses from Hand-Held Sprayers by Emanuele Cerruto, Giuseppe Manetto, Francesco Santoro, and Simone Pascuzzi. Protection of greenhouse crops in southern Italy usually requires 15-20 phytosanitary treatments per year, with volume rates in the range of 1000-2000 L ha ${ }^{-1}$, depending on the plant growth stage. The most widespread sprayers are hand-held, high-pressure devices, which may expose operators to high levels of pesticides. This paper, also with the aim to lead towards a more sustainable use of greenhouses in agricultural productions, including some aspects of workers' safety [26-30], reports the results of experimental tests aimed at measuring the amount of the mixture deposited on the worker's body (potential dermal exposure, PDE) during pesticide applications to tomato and strawberry plants in a protected environment. Experimental tests on tomatoes were carried out considering two plant growth stages (flowering and senescence), two types of spray lance, two working pressures ( 1 and $2 \mathrm{MPa}$ ), and two walking directions (forwards and backwards). Those on the strawberries were carried out at the maturity of the fruit growth stage, comparing two hand-held sprayers (a standard spray gun and a short hand-held spray boom equipped with two nozzles) and working according to the common practice: forwards movement of the operator and high pressure $(2 \mathrm{MPa})$. The results showed that with the tomato plants, the most important factor in reducing the deposit on the operator was the walking direction: on average, the PDE was $718 \mathrm{~mL}$ per $1000 \mathrm{~L}$ of the sprayed mixture $(0.72 \%)$ ) while walking forwards and $133 \mathrm{~mL}(0.13 \%)$ while walking backwards. The reduction factor ranged from 3.0 at the flowering growth stage to 7.2 at the senescence growth stage. With respect to the strawberry plants, the PDE was significantly higher when the operator used the short hand-held spray boom $(887 \mathrm{~mL}$ per $1000 \mathrm{~L}$ of the sprayed mixture, equivalent to $0.89 \%$ ), rather than the spray gun $(344 \mathrm{~mL}, 0.34 \% 0)$. In both cases, the most exposed body parts were the lower limbs, which accounted for $89-94 \%$ of the total PDE. The twelfth article is A New Approach to Land-Use Structure: Patch Perimeter Metrics as a Spatial Analysis Tool by Ilaria Zambon, Pere Serra, Silvia Pili, Vincenzo Bernardini, Carlotta Ferrara, and Luca Salvati. This work introduces a new class of landscape metrics characterizing basic features of patch perimeters. Specific computation on patch perimeters was carried out on fine-grained land-use maps with the aim to characterize spatial patterns of neighbor patches, evidencing contact points and perimeter length between two (or more) land-use types. A detailed set of class and landscape metrics were derived from such analysis. This approach is complementary to classical landscape metrics and proved to be particularly useful to characterize complex, fragmented landscapes profiling metropolitan regions based on integrated evaluations of their structural (landscape) and functional (land-use) organization. A multivariate analysis was run to characterize distinctive spatial patterns of the selected metrics in four metropolitan regions of southern Europe reflecting different morphological configurations (Barcelona: compact, polycentric; Lisbon: dispersed, mono-centric; Rome: dispersed, polycentric; and Athens: compact, mono-centric). Perimeter metrics assumed different values for each investigated land-use type, with peculiar characteristics associated with each city. Land-use types assessing residential, discontinuous urban patches were associated with particularly high values of perimeter metrics, possibly indicating patch fragmentation, spatially associated distribution of land-use types and landscape complexity. Multivariate analysis indicates substantial differences among cities, reflecting the range of morphological configurations described above (from compact mono-centric to dispersed polycentric) and suggesting that urban expansion is accompanied with multiple modifications in the use of the surrounding non-urban land. The computational approach proposed in this study and based on spatially explicit metrics of landscape configuration and proximity may reflect latent changes in local socio-spatial structures. Our results demonstrate that scattered urban expansion determines a polarization in suburban areas with highly fragmented and more homogeneous landscapes, respectively, associated with mixed cropland and forest systems. The fourteenth article is Worrying about "Vertical Landscapes": Terraced Olive Groves 
and Ecosystem Services in Marginal Land in Central Italy by Elena Brunori, Luca Salvati, Angela Antogiovanni and Rita Biasi. Terraced Mediterranean areas are distinctive man-made landscapes with historical and cultural relevance. Terraced land abandonment driven by physical and economic constraints had important ecological consequences. This study focuses on a marginal agricultural district in southern Latium, central Italy, where terracing dated back to the Roman period and olive groves are the main agricultural use. A diachronic assessment of land-use transformations was carried out to identify landscape dynamics and drivers of change around terraced land. Terraced landscape systems (TLS), derived from spatial aggregation of neighboring terraced patches, have been analyzed for landscape transformations considering slope as the main stratification variable. Structural and functional characteristics of TLS were analyzed using a landscape ecology approach. Soil bio-chemical indicators were finally assessed to study the impact of terraced olive agro-ecosystems on soil-related ecosystems services. The empirical findings outlined that TLS in central Italy are sensitive to urbanization and land abandonment. Cultivated terraces prevailed up to gentle-medium slope land, uncultivated and wooded areas dominated terraces on steep slopes. In this context, poly-cultural olive groves proved to be a cropping system particularly resilient to global change, irrespective of land slope. Terraced systems and extensive poly-cultural olive groves play a role in preserving ecosystem integrity, landscape quality, soil functionality and, therefore, environmental sustainability. The fifteenth article is Rural Districts between Urbanization and Land Abandonment: Undermining Long-Term Changes in Mediterranean Landscapes by Ilaria Zambon, Agostino Ferrara, Rosanna Salvia, Enrico Maria Mosconi, Luigi Fici, Rosario Turco, and Luca Salvati. The present study investigates changes in the rural landscapes of a Mediterranean country (Greece) over a long time period (1970-2015) encompassing economic expansions and recessions. Using a spatial distribution of five basic agricultural land-use classes (arable land, garden crop, vineyards, tree crop and fallow land) derived from official statistics at 6 years $(1970,1979,1988,1997,2006,2015)$, a quantitative analysis based on correlation and multivariate techniques was carried out to identify recent changes in the Greek agricultural landscape at prefectural level during different economic waves. Empirical results evidenced both intuitive and counter-intuitive landscape transformations, including: (i) a progressive, spatially homogeneous reduction of cropland; (ii) a (more or less) rapid decrease in the surface of high-input crops, including arable land, horticulture and vineyards; (iii) a parallel increase in the surface of tree crops, especially olive; (iv) a spatially heterogeneous decrease of fallow land concentrated in metropolitan and tourism districts, especially in the last decade; and, finally, (v) increasingly diversified landscapes in rural, accessible areas close to the sea coast. Based on a correlation analysis with background socioeconomic indicators, our findings reflect the multiple impacts of urbanization and land abandonment on the composition and diversity of rural landscapes. Changes in agricultural land use were molded by multiple drivers depending on latent transformations in rural systems and inherent conflicts with expanding urban regions. Together with market conditions and the Common Agricultural Policy subsidy regime, social contexts and the economic cycle are important when identifying long-term changes in agricultural landscapes, especially in transitional socio-ecological systems. Another article is Rethinking Sustainability within the Viticulture Realities Integrating Economy, Landscape and Energy by Ilaria Zambon, Andrea Colantoni, Massimo Cecchini and Enrico Maria Mosconi. Sustainability is often explained through three dimensions (society, economy, and environment). However, such a definition currently appears to be restricted. Sustainable development often includes the energy issue [1-8]. An example of realities founded on bioenergy are agro-energy districts [11]. These realities involve all three dimensions of sustainability, also integrating the energy dimension and fueling a potential circular economy. Based on these premises, the most affluent rural subdivision in Italy is that of wine. The wine sector has experienced a recent growth of its economic market, diverging from other agricultural activities and enlarging its cultivated surface areas. In this sense, the local landscape has also changed. Owing to the strong inclination of the wine sector in adopting sustainable strategies and measures, agro-energy districts can be the following future phase in viticulture realities as a cutting-edge business in the modern agricultural sector, implementing new strategies and opportunities [9]. 


\subsection{Technical Article}

The fifth article is Reusing Pruning Residues for Thermal Energy Production: A Mobile App to Match Biomass Availability with the Heating Energy Balance of Agro-Industrial Buildings by Carlo Bisaglia, Massimo Brambilla, Maurizio Cutini, Antonio Bortolotti, Guido Rota, Giorgio Minuti, and Roberto Sargiani. Using the pruning residues of woody crops can be beneficial in many ways (e.g., excellent energy balance, a net reduction in pollutant emission and a positive contribution to global warming control). This article describes the background work and development of a new support tool that will allow the user to know the amount and quality of pruning residue required to meet the energy requirements to heat both residential and agro-industrial buildings (e.g., greenhouses). Knowing the average amount of pruned biomass $\left(\mathrm{t} \mathrm{d} . \mathrm{m} . \mathrm{ha}^{-1}\right)$, the average lower heating value of wood $\left(4.00 \mathrm{kWh} \mathrm{kg}^{-1}\right)$ and the average efficiency of a woody biomass boiler (90\%) enabled the overall available net energy yearly amount $\left(\mathrm{kWh}_{\text {year }}{ }^{-1}\right)$ to be determined. This was compared to the overall energy requirements $\left(\mathrm{kWh}_{\mathrm{wear}}{ }^{-1}\right)$ of agro-industrial buildings, which are a result of their main features (e.g., maximum heatable surface, building energy classification and the climatic zone). Depending on user needs, the tool suggests the amount of required biomass and, if not entirely available, what amount of fossil fuels are required to fulfill the energy requirement. The algorithm output was compared with the results of two case studies carried out on seven farm buildings and nine greenhouses. Knowing the amount and energy potential of the available biomass allows for planning and evaluation of the planned benefits. Another article entitled Mathematical Model of the Plane-Parallel Movement of the Self-Propelled Root-Harvesting Machine by Volodymyr Bulgakov, Simone Pascuzzi, Francesco Santoro, and Alexandros Sotirios Anifantis. The harvest techniques and the employed machines are important factors in reducing soil loss due to root crop harvesting. Furthermore, the deviation of the working organs of the self-propelled sugar root-harvesting machines from the axis of the row also leads to significant losses and damage to sugar beetroots. Therefore, the self-propelled machine units must move in a horizontal plane with a high degree of accuracy. The purpose of this study is to increase the efficiency of the self-propelled harvester by analyzing its plane-parallel motion and evaluating its constructive and kinematic parameters. To determine the influence of these parameters on the plane-parallel motion of the self-propelled root-harvesting machine, its mathematical model has been calculated. Furthermore, experimental tests were executed in order to evaluate the degree of damage to sugar beetroot crops during their digging, depending on the magnitude of the deviations of the center of the digging tool. The results of this trials highlighted that if the crop row deviates from the conventional axis line by $10 \mathrm{~mm}$, the root crop damage exceeds is $21.7 \%$ and at deviations by $70 \mathrm{~mm}$, the damage exceeds $67 \%$. The theoretical study of the trajectory of the center of the outside digging tool and the experimental evaluation of its work (in terms of the quality of harvesting with deviations in its trajectory of motion) formally confirm the coincidence of all the studies-both theoretical and experimental. The use of the model of the plane-parallel movement of the self-propelled root-harvesting machine then improves the quality parameters of the technological process. The eleventh article is Machine Vision Retrofit System for Mechanical Weed Control in Precision Agriculture Applications by Federico Pallottino, Paolo Menesatti, Simone Figorilli, Francesca Antonucci, Roberto Tomasone, Andrea Colantoni and Corrado Costa. This paper presents a machine vision retrofit system designed for upgrading used tractors to allow the control of the tillage implements and enable real-time field operation. The retrofit package comprises an acquisition system placed in the cabin, a front-mounted Real-Time RGB camera sensor, and a rear-mounted Peiseler encoder wheel. The method combines shape analysis and colorimetric k-nearest neighbor ( $k-N N)$ clustering for in-field weed discrimination. This low-cost retrofit package can use interchangeable sensors, supplying flexibility of use with different farming implements. Field tests were conducted within lettuce and broccoli crops to develop the image analysis system for the autonomous control of an intra-row hoeing implement [31,32]. The performance showed by the system in the trials was judged in terms of accuracy and speed. The system was capable of discriminating weed plants from crop with few errors, achieving a fairly high performance, given the severe degree of weed infestation encountered. 
The actuation time for image processing, currently implemented in MATLAB integrated with the retrofit kit, was about $7 \mathrm{~s}$. The correct detection rate was higher for lettuce (from $69 \%$ to $96 \%$ ) than for broccoli (from $65 \%$ to $79 \%$ ), also considering the negative effect of shadows. To be implementable, the experimental code needs to be optimized to reduce acquisition and processing times. A software utility was developed in Java to reach a processing time of two images per second. The thirteenth article is Building Energy Opportunity with a Supply Chain Based on the Local Fuel-Producing Capacity by Flavio Andreoli Bonazzi, Sirio R. S. Cividino, Ilaria Zambon, Enrico Maria Mosconi and Stefano Poponi. Studying and modeling plants for producing electric power obtained from vegetal wood cellulose biomass can become an opportunity for building a supply chain based on the local fuel-producing capacity. Focusing on energy-producing technologies, such as pyrolysis or gasification, the present work assessed the amount of vegetal biomass that may be used as fuel, both in terms of actual availability and supply price, in the Province of Rieti (Italy). The aim is to draw up a supply plan that has an intrinsic relationship with the local area. The results confirmed a production of $24 \mathrm{MW}$ of project thermal power and $4 \mathrm{MW}$ of project electric power. The ensuing plant was then studied following current norms about renewable energy, environmental consistency, and atmospheric emissions. An economic analysis of the cost investment was also carried out, where the total return is approximately of $19 \%$. The results exposed that plant costs are acceptable only if short-supply chain fuel is purchased. The costs of generating energy from agro-forestry biomass are certainly higher; however, the plant represents a significant territorial opportunity, especially for the economic sectors of agriculture and forestry. The employment effect plays a central role in the concession process, which is relevant for the interaction among renewable energy production and agriculture [33,34]. The environmental impact of a biomass plant from agro-forestry residues can be measured exclusively on atmospheric emissions: the plant must be placed in industrial areas without any landscape or naturalistic value. The sixteenth article is Solar Radiation Distribution inside a Greenhouse Prototypal with Photovoltaic Mobile Plant and Effects on Flower Growth by Andrea Colantoni, Danilo Monarca, Alvaro Marucci, Massimo Cecchini, Ilaria Zambon, Federico Di Battista, Diego Maccario, Maria Grazia Saporito and Margherita Beruto. The diffusion of renewable energy requires the search for new technologies useful for obtaining good energy and production efficiency. Even if the latter is not always easy to obtain, the integration of photovoltaic panels on the roof of greenhouses intended for floriculture can represent an alternative [35]. The present paper evaluates climatic conditions inside a greenhouse, in which $20 \%$ of its roof surface has been replaced with mobile photovoltaic (PV) panels. The PV system implemented in this study can vary the light energy collection surface in relation to the degree of insolation. The aim is to observe the shading effects of the PV system on the growth of several varieties of flowers (iberis, mini-cyclamens and petunias) to ensure the use of solar energy as an income integration deriving from floricultural production. In fact, in agronomic terms, it has ensured: (i) to be able to shade the underlying environment in most lighting conditions; and (ii) to let through more light when it is required for the needs of crop plants or in cloudy weather [36,37]. Results have described the distribution of solar radiation, variability of temperature and humidity and lighting in a solar year and the observed outcomes on floristic production. The seventeenth article is Photovoltaic and Hydrogen Plant Integrated with a Gas Heat Pump for Greenhouse Heating: A Mathematical Study by Alexandros Sotirios Anifantis, Andrea Colantoni, Simone Pascuzzi and Francesco Santoro. Nowadays, the traditional energy sources used for greenhouse heating are fossil fuels, diesel, and natural gas. The global energy demand will continue to grow, and alternative technologies need to be developed in order to improve the sustainability of crop production in protected environments. Innovative solutions are represented by renewable energy plants such as photovoltaic, wind and geothermal integrated systems [38]; however, these technologies need to be connected to the power grid in order to store the energy produced [39-42]. On agricultural land, power grids are not widespread and stand-alone renewable energy systems should be investigated especially for greenhouse applications. The aim of this research is to analyze, by means of a mathematical model, the energy efficiency of a photovoltaic $(8.2 \mathrm{~kW})$, hydrogen $(2.5 \mathrm{~kW})$ and ground source gas heat pump $(2.2 \mathrm{~kW})$ integrated 
in a stand-alone system used for heating an experimental greenhouse tunnel $\left(48 \mathrm{~m}^{2}\right)$ during the winter season. A yearlong energy performance analysis was conducted for three different types of greenhouse cover materials, a single layer polyethylene film, an air inflated-double layer polyethylene film, and a double acrylic or polycarbonate. The results of one year showed that the integrated system had a total energy efficiency of $14.6 \%$. Starting from the electric energy supplied by the photovoltaic array, the total efficiency of the hydrogen and ground source gas heat pump system was $112 \%$ if the coefficient of the performance of the heat pump is equal to 5 . The heating system increased the greenhouse air temperatures by $3-9{ }^{\circ} \mathrm{C}$ with respect to the external air temperatures, depending on the greenhouse cover material used. The nineteenth is Thermal and Fluid Dynamic Analysis within a Batch Micro-Reactor for Biodiesel Production from Waste Vegetable Oil by Maurizio Carlini, Sonia Castellucci and Andrea Mennuni. Biofuels represent an alternative solution to petroleum-based fuels. In particular, biodiesel is very interesting, especially if it is produced from waste vegetable oil. Biodiesel can be used in diesel engines. The aim of this work is to implement a 2D numerical analysis in Comsol Multiphysics in order to verify a uniform temperature field within a non-isothermal batch mixed micro-reactor. An immersion heater system has been studied as a suitable solution to increase the temperature of WVO (Waste Vegetable Oil) before the start of the transesterification reaction. Thus, the efficiency of the immersion heating system has been investigated. The results show that the temperature field is not uniform within the fluid domain, because of the convective flux with the external environment. These conditions could lead to a low overall conversion rate. The other article is Analysis of the Possibilities of Using a Heat Pump for Greenhouse Heating in Polish Climatic Conditions-A Case Study by Artur Nemś, Magdalena Nemś and KlaudiaŚwider. This article presents an analysis of selecting a seasonal heating system for an existing greenhouse. The analyzed object is located in Poland near Wroclaw, where summer flowers are grown. Appropriate thermal conditions must be ensured continuously for four heating months. The primary source of heat in the examined flower greenhouse was a coal-fired furnace. The analysis presented in the article shows a method of thermal balancing the object, determining heat demands in the analyzed period using the experiment plan, and also selecting a new heating system in the form of a heat pump. The analysis of the operation of the heating system was performed for air and ground source heat pumps to determine the profitability of their application in Polish climatic conditions. An economic analysis was also included and the investment impact on pollution emissions was calculated.

\subsection{Commentary}

The last article is a commentary entitled Latent Drivers of Landscape Transformation in Eastern Europe: Past, Present and Future by Marcela Prokopová, Ondřej Cudlín, Renata Včeláková, Szabolcs Lengyel, Luca Salvati and Pavel Cudlín. Land-use changes in Europe have been influenced by social forces including economic, demographic, political, technological, and cultural factors. Contributing to a refined conceptualization of multifaceted processes of landscape transformation in the European continent, the present study proposes an extensive review of land-use trends in Eastern Europe, focusing on past, present and future conditions that may characterize latent drivers of change. Three time periods with a specific institutional, political and socioeconomic context reflecting distinct processes of land-use change were identified including: (i) the rapid transition to a centralized political system since the early 1950s (up to the late 1980s); (ii) a progressive transition from communist regimes to parliamentary democracy in 1989-1990 (up to the early 2000s); and (iii) the subsequent accession of individual countries to the European Union (2004-2007) up to nowadays. The most recent land-use trends are increasingly influenced by European directives on the environment, while national policies continue to shape economic development in member states. 


\section{Conclusions}

In summary, the papers in the special issue present some of the latest and most promising research results in this new and exciting field, which continues to make significant impact on real-world applications. We are confident that this special issue will stimulate further research in this area.

Acknowledgments: The research was partially supported by MIUR (Italian Minister for education, University and Research) in the context of the initiative "Department of excellence", Law 232/216. We thank all authors of the special issue.

Conflicts of Interest: The authors declare no conflict of interest.

\section{References}

1. Bianchi, B.; Tamborrino, A.; Santoro, F. Assessment of the energy and separation efficiency of the decanter centrifuge with regulation capability of oil water ring in the industrial process line using a continuous method. J. Agric. Eng. 2013, 44. [CrossRef]

2. Marucci, A.; Zambon, I.; Colantoni, A.; Monarca, D. A combination of agricultural and energy purposes, Evaluation of a prototype of photovoltaic greenhouse tunnel. Renew. Sustain. Energy Rev. 2018, 82, 1178-1186. [CrossRef]

3. Colantoni, A.; Allegrini, E.; Boubaker, K.; Longo, L.; Di Giacinto, S.; Biondi, P. New insights for renewable energy hybrid photovoltaic/wind installations in Tunisia through a mathematical model. Energy Convers. Manag. 2013, 75, 398-401. [CrossRef]

4. Monarca, D.; Cecchini, M.; Colantoni, A.; Marucci, A. Feasibility of the electric energy production through gasification processes of biomass, technical and economic aspects. In International Conference on Computational Science and Its Applications; Springer: Berlin/Heidelberg, Germany, 2011; pp. 307-315.

5. Anifantis, A.S.; Colantoni, A.; Pascuzzi, S. Thermal energy assessment of a small scale photovoltaic, hydrogen and geothermal stand-alone system for greenhouse heating. Renew. Energy 2017, 103, 115-127. [CrossRef]

6. Zambon, I.; Colantoni, A.; Cecchini, M.; Mosconi, E.M. Rethinking sustainability within the viticulture realities integrating economy, landscape and energy. Sustainability 2018, 10, 320. [CrossRef]

7. Salerno, M.; Gallucci, F.; Pari, L.; Zambon, I.; Sarri, D.; Colantoni, A. Costs-benefits analysis of a small-scale biogas plant and electric energy production. Bulg. J. Agric. Sci. 2017, 23, 357-362.

8. Colantoni, A.; Zambon, I.; Cecchini, M.; Marucci, A.; Piacentini, L.; Feltrin, S.; Monarca, D. Greenhouses plants as a landmark for research and innovation: The combination of agricultural and energy purposes for a more sustainable future in Italy. Chem. Eng. Trans. 2017, 58, 469-474.

9. Colantoni, A.; Delfanti, L.; Recanatesi, F.; Tolli, M.; Lord, R. Land use planning for utilizing biomass residues in Tuscia Romana (central Italy): Preliminary results of a multi criteria analysis to create an agro-energy district. Land Use Policy 2016, 50, 125-133. [CrossRef]

10. Mosconi, E.M. Opportunity and function of energy wholesale market in Italy. Rivista Giuridica dell'ambiente 2003, 18, 1101-1110.

11. Febbi, P.; Menesatti, P.; Costa, C.; Pari, L.; Cecchini, M. Automated determination of poplar chip size distribution based on combined image and multivariate analyses. Biomass Bioenergy 2015, 73, 1-10. [CrossRef]

12. Monarca, D.; Cecchini, M.; Guerrieri, M.; Colantoni, A. Conventional and alternative use of biomasses derived by hazelnut cultivation and processing. In Proceedings of the VII International Congress on Hazelnut, Viterbo, Italy, 2008; pp. 627-634. [CrossRef]

13. Pascuzzi, S.; Santoro, F. Exposure of farm workers to electromagnetic radiation from cellular network radio base stations situated on rural agriculturalland. Int. J. Occup. Saf. Ergon. 2015, 21, 351-358. [CrossRef] [PubMed]

14. Biasi, R.; Colantoni, A.; Ferrara, C.; Ranalli, F.; Salvati, L. In-between sprawl and fires, long-term forest expansion and settlement dynamics at the wildland-urban interface in Rome, Italy. Int. J. Sustain. Dev. World Ecol. 2015, 22, 467-475. [CrossRef]

15. Cecchini, M.; Zambon, I.; Pontrandolfi, A.; Turco, R.; Colantoni, A.; Mavrakis, A.; Salvati, L. Urban sprawl and the 'olive' landscape: Sustainable land management for 'crisis' cities. GeoJournal 2018, 1-19. [CrossRef]

16. Colantoni, A.; Mavrakis, A.; Sorgi, T.; Salvati, L. Towards a 'polycentric' landscape? Reconnecting fragments into an integrated network of coastal forests in Rome. Rend. Lincei 2015, 26, 615-624. [CrossRef] 
17. Monarca, D.; Cecchini, M.; Colantoni, A. Plant for the production of chips and pellet: Technical and economic aspects of an case study in the central Italy. In International Conference on Computational Science and Its Applications; Springer: Berlin/Heidelberg, Germany, 2011; pp. 296-306.

18. Colantoni, A.; Mazzocchi, F.; Laurendi, V.; Grigolato, S.; Monarca, F.; Monarca, D.; Cecchini, M. Innovative solution for reducing the run-down time of the chipper disc using a brake clamp device. Agriculture 2017, 7, 71. [CrossRef]

19. Pascuzzi, S.; Santoro, F.; Panaro, V.N. Investigation of workers' exposures to vibrations produced by portable shakers. Choice 2009, 50, 11.

20. Pascuzzi, S. The effects of the forward speed and air volume of an air-assisted sprayer on spray deposition in tendone trained vineyards. J. Agric. Eng. 2013, 44, 18. [CrossRef]

21. Cividino, S.R.S.; Pergher, G.; Zucchiatti, N.; Gubiani, R. Agricultural health and safety survey in Friuli Venezia Giulia. Agriculture 2018, 8, 9. [CrossRef]

22. Cecchini, M.; Colantoni, A.; Monarca, D.; Cossio, F.; Riccioni, S. Survey on the status of enforcement of European directives on health and safety at work in some farms of central Italy. Chem. Eng. Trans. 2017, 58, 103-108.

23. Marucci Monarca, D.; Cecchini, M.; Colantoni, A.; Cappuccini, A. The heat stress for workers employed in laying hens houses. J. Food Agric. Environ. 2013, 11, 20-24.

24. Monarca, D.; Colantoni, A.; Cecchini, M.; Longo, L.; Vecchione, L.; Carlini, M.; Manzo, A. Energy characterization and gasification of biomass derived by hazelnut cultivation: Analysis of produced syngas by gas chromatography. Math. Probl. Eng. 2012, 2012, 102914. [CrossRef]

25. Di Giacinto, S.; Colantoni, A.; Cecchini, M.; Monarca, D.; Moscetti, R.; Massantini, R. Dairy production in restricted environment and safety for the workers. Ind. Aliment. 2012, 530, 5-12.

26. Colantoni, A.; Marucci, A.; Monarca, D.; Pagniello, B.; Cecchini, M.; Bedini, R. The risk of musculoskeletal disorders due to repetitive movements of upper limbs for workers employed to vegetable grafting. J. Food Agric. Environ. 2012, 10, 14-18.

27. Cecchini, M.; Cossio, F.; Marucci, A.; Monarca, D.; Colantoni, A.; Petrelli, M.; Allegrini, E. Survey on the status of enforcement of European directives on health and safety at work in some Italian farms. J. Food Agric. Environ. 2013, 11, 595-600.

28. Cividino, S.R.S.; Pergher, G.; Gubiani, R.; Moreschi, C.; DaBroi, U.; Vello, M.; Rinaldi, F. Definition of a methodology for gradual and sustainable safety improvements on farms and its preliminary applications. Agriculture 2018, 8, 7. [CrossRef]

29. Cecchini, M.; Monarca, D.; Laurendi, V.; Puri, D.; Cossio, F. Mechatronic Solutions for the Safety of Workers Involved in the Use of Manure Spreader. Agriculture 2017, 7, 95. [CrossRef]

30. Marucci, A.; Colantoni, A.; Zambon, I.; Egidi, G. Precision farming in hilly areas: The use of network RTK in GNSS technology. Agriculture 2017, 7, 60. [CrossRef]

31. Zambon, I.; Delfanti, L.; Marucci, A.; Bedini, R.; Bessone, W.; Cecchini, M.; Monarca, D. Identification of optimal mechanization processes for harvesting Hazelnuts based on geospatial technologies in Sicily (Southern Italy). Agriculture 2017, 7, 56. [CrossRef]

32. Ruggieri, A.; Braccini, A.M.; Poponi, S.; Mosconi, E.M. A meta-model of inter-organisational cooperation for the transition to a circular economy. Sustainability 2016, 8, 1153. [CrossRef]

33. Ruggieri, A.; Mosconi, E.M.; Poponi, S.; Silvestri, C. Digital innovation in the job market: An explorative study on cloud working platforms. In Lecture Notes in Information Systems and Organisation; Springer: Cham, Switzerland, 2016.

34. Colantoni, A.; Monarca, D.; Marucci, A.; Cecchini, M.; Zambon, I.; Di Battista, F.; Beruto, M. Solar Radiation Distribution inside a Greenhouse Prototypal with Photovoltaic Mobile Plant and Effects on Flower Growth. Sustainability 2018, 10, 855. [CrossRef]

35. Villarini, M.; Cesarotti, V.; Alfonsi, L.; Introna, V. Optimization of photovoltaic maintenance plan by means of a FMEA approach based on real data. Energy Convers. Manag. 2017, 152, 1-12. [CrossRef]

36. Mosconi, E.M.; Carlini, M.; Castellucci, S.; Allegrini, E.; Mizzelli, L.; di Trifiletti, M.A. Economical assessment of large-scale photovoltaic plants: An Italian case study. In International Conference on Computational Science and Its Applications; Springer: Berlin/Heidelberg, Germany, 2013; pp. 160-175.

37. Russo, G.; Anifantis, A.S.; Verdiani, G.; Mugnozza, G.S. Environmental analysis of geothermal heat pump and LPG greenhouse heating systems. Biosyst. Eng. 2014, 127, 11-23. [CrossRef] 
38. Manetto, G.; Cerruto, E.; Pascuzzi, S.; Santoro, F. Improvements in citrus packing lines to reduce the mechanical damage to fruit. Chem. Eng. Trans. 2017, 58, 391-396.

39. Pascuzzi, S. A multibody approach applied to the study of driver injuries due to a narrow-track wheeled tractor rollover. J. Agric. Eng. 2015, 46, 105-114. [CrossRef]

40. Pascuzzi, S.; Cerruto, E. An innovative pneumatic electrostatic sprayer useful for tendone vineyards. J. Agric. Eng. 2015, 3, 123-127. [CrossRef]

41. Pascuzzi, S.; Cerruto, E.; Manetto, G. Foliar spray deposition in a "tendone" vineyard as affected by airflow rate, volume rate and vegetative development. Crop Prot. 2016, 91, 34-48. [CrossRef]

42. Baldoin, C.; Balsari, P.; Cerruto, E.; Pascuzzi, S.; Raffaelli, M. Improvement in pesticide application on greenhouse crops: Results of a survey about greenhouse structures in Italy. Acta Hortic. 2008, 801, 609-614. [CrossRef]

(C) 2018 by the authors. Licensee MDPI, Basel, Switzerland. This article is an open access article distributed under the terms and conditions of the Creative Commons Attribution (CC BY) license (http://creativecommons.org/licenses/by/4.0/). 